\title{
The effect of novel environment and sex on the additive genetic variation and covariation in and between emergence body weight and development period in the cowpea weevil, Callosobruchus maculatus (Coleoptera, Bruchidae)
}

\author{
JOHN GUNTRIP, RICHARD M. SIBLY \& GRAHAM J. HOLLOWAY* \\ School of Animal and Microbial Science, University of Reading, Whiteknights, PO Box 228, Reading RG6 6AJ, U.K.
}

\begin{abstract}
Progeny from full-sib/half-sib families of a population of Callosobruchus maculatus near genetic equilibrium were reared either in an ancestral $\left(30^{\circ} \mathrm{C}, 70\right.$ per cent relative humidity) or in a novel $\left(25^{\circ} \mathrm{C}, 45\right.$ per cent relative humidity) environment. The life history traits, emergence body weight and development period were measured in both sexes. Insects developed faster and emerged heavier at a higher temperature and humidity. For both sexes, in the ancestral environment additive genetic variation and 'narrow-sense' heritability estimates were higher for body weight, the morphological trait, than for development period, the primary fitness trait. For both sexes, matrix analyses revealed significant differences between the estimated additive genetic variance-covariance $(\mathrm{G})$ matrices from each environment. In the novel environment, the evolved genetic architecture appeared to break down, possibly as a result of novel gene expression; the trade-off between emergence body weight and development period was disrupted with an associated increase in additive genetic variation for both life history traits. In both environments, female insects developed more slowly and emerged heavier than male insects. Matrix analyses show significant differences between the G-matrices of each sex, suggesting that different constraints may operate in the two sexes.
\end{abstract}

Keywords: Callosobruchus maculatus, G-matrix, genetic variation, novel environment, tradeoff.

\section{Introduction}

The theory of the genetics of life history evolution has made great progress since Lande's (1979) consideration of the problem. The expectation is that, in a population at selective equilibrium, a genetic trade-off with a correlation coefficient of -1 should exist between two traits that compete for a share of a limited resource (Charnov, 1989) (i.e. a simple bivariate interaction), this resource often being energy (Sibly \& Calow, 1986). A genetic tradeoff between such traits develops because of the accumulation of genes with antagonistic pleiotropic effects (Rose, 1982). When antagonistic pleiotropy

\footnotetext{
*Correspondence. E-mail: g.j.holloway@reading.ac.uk
}

operates, a favoured change in one trait is associated with a disfavoured change in a second trait. These genes are consequently driven to fixation only very slowly by natural selection so that significant levels of additive genetic variation are expected to be maintained. Many empirical studies have been carried out to investigate the genetic architecture underpinning trade-offs. Some have successfully demonstrated the predicted genetic structure (e.g. Simmons et al., 1980; Rose \& Charlesworth, 1981; Soliman, 1982; Luckinbill et al., 1984; Møller et al., 1989; Holloway et al., 1990a), but at least as many studies have not (e.g. Giesel \& Zettler, 1980; Giesel et al., 1982; Murphy et al., 1983; Stearns, 1983; Bell, 1984a,b). Many of these studies have been criticized for using small or laboratory inbred populations (Rose, 1984). 
Roff \& Mousseau (1987) and Lessells (1991) reviewed the empirical evidence for the existence of genetic trade-offs between life history traits in Drosophilid and non-Drosophilid species, respectively, and concluded that most studies have failed to find predicted values. Genetic trade-offs can be overwhelmed by variation in resource acquisition (van Noordwijk \& de Jong, 1986), obscured by hierarchical resource allocation (de Laguerie et al., 1991), and life history traits do not always interact in a simple bivariate manner (Charlesworth, 1990). Such complexities in trait interactions can produce genetic correlations significantly greater than -1 and sometimes even opposite to that predicted (Charlesworth, 1990). The outcome is that, despite all of the work that has been carried out to date, the generality of the existence of genetic trade-offs between resource-demanding life history traits is still uncertain (Scheiner et al., 1989).

A further very important factor influencing the genetic structure underlying trade-offs is the environment in which the experimental work is carried out. As most quantitative genetic studies of life histories are carried out under artificial laboratory conditions, the effect of novel environment would appear to be very significant. Even so, very few empirical studies have addressed this problem (Service \& Rose, 1985; Holloway et al., 1990a; Kawecki, 1995). Holloway et al. (1990a) predicted and presented data confirming that one effect of novel environment would be to increase the level of additive genetic variation owing to novel gene expression. However, Kawecki (1995) did not find similar results using the cowpea weevil, Callosobruchus maculatus. Service \& Rose (1985) further demonstrated that novel environment should result in the breakdown of adapted genetic correlations between characters involved in trade-offs, a finding further supported by Holloway et al. (1990a).

It has been conventional in the study of life history evolution to analyse fitness primarily in relation to females, as fitness in relation to males is generally more difficult to measure and, subsequently, model (Sibly \& Calow, 1986). In many insect species, however, sexual dimorphism in life history traits, such as emergence body weight or development period, is often very evident. In addition to this, Holloway et al. (1993) showed that estimates of additive genetic variation and covariation in and between life history traits differed between the sexes in a population of the two-spot ladybird, Adalia bipunctata. This suggests that each sex may be subject to a different set of constraints that is reflected in the structure of the life history genetics.
Møller et al. (1989) identified a trade-off between emergence body weight and development period in female $C$. maculatus. This trade-off does not represent an allocation problem as described above, but female weevils trade off the advantages of being larger with the associated benefits of higher fecundity against the costs of having to develop longer to achieve larger size (Sibly \& Calow, 1986). For males, emerging earlier may offer greater access to more virgin females, but the shorter the development time, the smaller the emergence weight; and size is a sexually selected character in some weevils (Holloway \& Smith, 1987). The relationship between development time and body weight in $C$. maculatus provided an ideal opportunity to examine the effects of novel environment and sex on the genetic structure underpinning a trade-off (but note that this trade-off would result in the evolution of a positive rather than a negative genetic correlation, as increasing development time is not favourable in evolutionary terms).

The present study therefore had three primary aims:

1 to investigate the genetics of the trade-off between emergence body weight and development period (egg to emergent adult) in $C$. maculatus (strain 'Campinas');

2 to determine the effect of novel environment on this trade-off;

3 to establish whether there are sex differences in the estimated genetic parameters.

The study was carried out using a population that had been cultured on the substrate greengram, Vigna radiata (family Leguminosae), for 45 discrete generations at constant density, temperature and humidity. Whether or not the population had reached equilibrium under these conditions is not possible to confirm, although some studies would suggest that this is long enough for a population to adapt to its environment (Bergeson \& Wool, 1988). The culture conditions are referred to here as the ancestral environment and the genetics of the tradeoff were tested in this environment and also a novel environment of lower temperature and humidity. Temperature is known to affect a range of life history traits in various Callosobruchus species (Giga \& Smith, 1983).

Following Holloway et al. (1990a,b) it was predicted that:

1 in the ancestral environment there would be significant amounts of additive genetic variation for emergence body weight and development period 
and that there would also be significant positive additive genetic covariation (reflecting a genetic trade-off) between these two life history traits;

2 estimated additive genetic variance-covariance (G) matrices would be significantly different between environments;

3 in the novel environment, estimated additive genetic variation for emergence body weight and development period would be higher in magnitude than in the ancestral environment (Holloway et al., 1990b; Smith et al., 1993);

4 in the novel environment, the positive additive genetic covariation between both traits found in the ancestral environment would break down by becoming more negative (Bell \& Koufopanou, 1986; Holloway et al., 1990b).

\section{Materials and methods}

\section{Culture techniques}

Beetles were cultured on greengram ( $V$. radiata) at constant temperature and humidity $\left[\mathrm{CTH} ; 30 \pm 1^{\circ} \mathrm{C}\right.$ and $70 \pm 5$ per cent relative humidity $(\mathrm{RH})]$. To initiate a culture, 300 adults were placed on $150 \mathrm{~g}$ of substrate in $850 \mathrm{~mL}$ glass jars. Culture jars were placed in risella oil (Shell Lubricants, U.K.) to prevent invasion by mites and cross-contamination. The culture interval was 22-28 days. Large numbers of individuals were always used to initiate cultures to minimize the effects of inbreeding (Wright, 1931). Inbreeding is known to reduce net fitness (Mackay, 1985) and may produce a number of inferior genotypes, which could result in spurious genetic correlations (Rose, 1984). Before use, all greengram was disinfected by freezing at $-18^{\circ} \mathrm{C}$ for 1 week and placed in store at $4^{\circ} \mathrm{C}$ for a further 2 weeks. Experimental seed was allowed to equilibrate to room temperature for 1 week. The insects had been maintained under the above conditions for 45 generations and as two separate lines.

\section{Experimental design}

The experiments were carried out under CTH conditions. Four days before insects were due to start emerging from culture, 500 seeds with eggs attached were randomly collected from the two lines, each seed isolated in a glass tube $(5 \times 1 \mathrm{~cm})$ and then observed daily for emerging insects. Freshly emerged insects were collected every $24 \mathrm{~h}$ from day 1 of emergence to day 7 and each isolated individually in a glass tube. If two or more insects emerged from a tube on the same day, then all were discarded to ensure that only virgins were collected. On the seventh day of emergence, 40 randomly chosen males (sires) were each mated with four randomly chosen females (dams) (i.e. in a fullsib/half-sib breeding design). After $24 \mathrm{~h}$, each dam was isolated in a glass tube and the sires were discarded. The dams were allowed to oviposit on $10 \mathrm{~g}$ of substrate for $24 \mathrm{~h}$ and then also discarded. Eggs were left for 3 days to ensure that all eggs had hatched [the colour of eggs changes from opaque yellow to white if larvae have successfully hatched and started boring into the seed (R. H. Smith, personal communication)]. To minimize 'withinseed' density effects, only seeds carrying either one or two white eggs were collected from each tube. Ten eggs from each half-sib family were randomly assigned to a glass tube and reared in the ancestral environment $\left(30 \pm 1^{\circ} \mathrm{C}, 70 \pm 5\right.$ per cent $\left.\mathrm{RH}\right)$, and another 10 eggs were placed into a second glass tube at $25 \pm 1^{\circ} \mathrm{C}, 45 \pm 5$ per cent $\mathrm{RH}$ (i.e. the novel environment). All tubes were randomly distributed in the CTH room to alleviate any localized environmental effects. All tubes were inspected daily for emerging progeny. Emerging progeny were sexed using the characteristics described by Southgate $e t$ al. (1957), their development period (to the nearest $24 \mathrm{~h}$ ) recorded, and then each individually dried in an oven at $65 \pm 2{ }^{\circ} \mathrm{C}$ for a period of 7 days. Individual dry body weights were obtained using a Cahn 29 electrobalance to the nearest $0.01 \mathrm{mg}$. There were 39 sires, each mated to four dams, and approximately four female and four male progeny per dam were weighed from each environment. A total of 30 female and 30 male progeny were randomly selected and weighed before and after being placed in the oven in order to obtain the relationship between dry and wet emergence body weight.

\section{Statistical analysis}

The data were derived from a nested full-sib/half-sib breeding design and analysed using the SAS General Linear Modelling (GLM) procedure (SAS Institute, 1989). The linear model used to analyse data from each environment was:

$Y_{i j k}=\mu+\alpha_{i}+\beta_{i j}+E_{i j k}$,

where $Y_{i j k}$ is the record of the $k$ th progeny of the $j$ th dam mated to the $i$ th sire, $\mu$ is the common mean, $\alpha_{i}$ is the effect of the $i$ th sire, $\beta_{i j}$ is the effect of the $j$ th dam mated to the $i$ th sire and $E_{i j k}$ is the uncontrolled environmental and genetic deviations attributable to individuals.

The causal additive genetic variation for each trait 
was estimated from the 'sire' and 'dam(sire)' mean square values in the ANOVA tables (Falconer, 1989) as follows:

$$
V_{A(s)}=4 x \frac{\mathrm{MS}(s)-\mathrm{MS}(d)}{d k}
$$

where $V_{A(s)}$ is the additive genetic variation estimated from the sire; $\operatorname{MS}(s)$ and $\operatorname{MS}(d)$ are the mean squares of the sire and dam(sire) treatments respectively, $d$ is the number of dams mated to each sire and $k$ is the number of progeny measured for each dam. 'Narrow-sense' heritabilities $\left(h^{2}\right)$ for each trait are calculated as the ratio of additive genetic variation to total phenotypic variation (Becker, 1984). Only 'narrow-sense' heritabilities are presented in the present study.

Analyses of covariance between both traits were carried out as outlined in Kempthorne (1957, pp. 264-265) using the equation:

$$
\mathrm{SP}(x y)=1 / 2[\mathrm{SS}(x+y)-\mathrm{SS}(x)-\mathrm{SS}(y)]
$$

where $x$ and $y$ are two traits, SP are sums of products and SS are sums of squares. Additive genetic correlation coefficients between traits are calculated as the additive genetic covariation between traits divided by the square root of the additive genetic variation for emergence body weight multiplied by the additive genetic variation for development period.

Traditional methods of calculating standard errors for variance and covariance components were employed (Becker, 1984), but it must be emphasized that these rely on the independence of estimated mean squares, which only occurs with balanced data sets (Sokal \& Rohlf, 1981). The data set presented here, as with most quantitative genetic data sets, is unbalanced (although not badly so), so standard errors may be biased to an unknown extent and direction (Searle, 1971) and must be viewed with some caution. However, it is at present evident that the least squares method of calculation yields estimates that frequently do not differ significantly from those produced by more involved procedures, such as restricted maximum likelihood (Knott et al., 1995) and jackknifing (Li \& Margolis, 1994), although, again, this rather depends on how unbalanced the data set is.

Estimates of additive genetic variances and covariances in and between the two measured traits are presented in the form of G-matrices (e.g. see Holloway et al., 1993) and also as matrices composed of $h^{2}$ and additive genetic correlation coefficients (e.g. see Møller et al., 1989). Both types of matrices are composed of complementary information and are here used to describe the two-dimensional genetic architecture for each sex in each environment.

G-matrices are compared using a Mahalanobis $D^{2}$ test (Krzanowski, 1988). This test is a maximum likelihood procedure that involves calculating the weighted determinants of the two matrices separately and subtracting these values from the determinant of the joint matrix. The $-2 \log _{e} \lambda$ value obtained is asymptotically distributed as $\chi^{2}$, thus the similarity of the two matrices can be assessed (note that the test provides information on the structure of the matrices, not the content).

\section{Results}

Dry body weight was found to be highly correlated with wet body weight $(r>+0.9)$ for both female and male insects.

\section{Phenotypic estimates of the life history traits in the ancestral and novel environment}

Phenotypic values for dry emergence body weight and development period are shown in Table 1 for each sex. Both female and male insects emerged heavier in the ancestral environment than in the novel environment $\left(F_{1,1034}=32.5, P<0.0001\right.$, and $F_{1,1104}=43.2, P<0.0001$, respectively) and developed more quickly $\left(F_{1,1034}=214, \quad P<0.0001\right.$, and $F_{1,1104}=220, P<0.0001$, respectively).

There were significant sex differences in both environments: females were heavier at emergence and also developed more slowly than male insects in the ancestral environment $\left(F_{1,1079}=5561, P<0.0001\right.$, and $F_{1,1079}=25.99, P<0.0001$, respectively) and also in the novel environment $\left(F_{1,1059}=5409, P<0.0001\right.$, and $F_{1,1059}=43.4, P<0.0001$, respectively).

\section{Genetic estimates of the life history traits}

Table 2a shows additive genetic variance-covariance (G) matrices for female and male insects emerging in the ancestral environment. Table 3a shows the estimates of heritabilities and additive genetic correlation coefficients for the same insects. Both female and male insects showed significant levels of additive genetic variation for emergence dry body weight, but estimates for development period were associated with large standard errors (Table 2a). For both sexes, therefore, heritabilities for emergence dry body weight were significantly different from zero, whereas those for development period were not (Table 3a). 
Table 1 Mean values ( \pm standard errors) of dry emergence body weight $(\mathrm{mg})$ and egg to adult development period (days) of Callosobruchus maculatus in the ancestral $\left(30^{\circ} \mathrm{C}, 70 \% \mathrm{RH}\right)$ and novel $\left(25^{\circ} \mathrm{C}, 45 \% \mathrm{RH}\right)$ environment

\begin{tabular}{llcccc}
\hline Life history trait & Sex & $n$ & $30^{\circ} \mathrm{C}, 70 \% \mathrm{RH}$ & $n$ & $25^{\circ} \mathrm{C}, 45 \% \mathrm{RH}$ \\
\hline Dry body weight & Female & 531 & $2.75 \pm 0.0115$ & 505 & $2.66 \pm 0.0114$ \\
& Male & 550 & $1.75 \pm 0.0073$ & 556 & $1.68 \pm 0.0074$ \\
Development period & Female & 531 & $23.3 \pm 0.0605$ & 505 & $24.5 \pm 0.0542$ \\
& Male & 550 & $22.9 \pm 0.045$ & 556 & $24.0 \pm 0.0544$ \\
\hline
\end{tabular}

$n$, sample size.

Table 2 Additive genetic variance-covariance matrices for female and male Callosobruchus maculatus for dry emergence body weight (wt; $\mathrm{mg}$ ) and development period (dev; days) in (a) the ancestral environment $\left(30^{\circ} \mathrm{C}, 70 \% \mathrm{RH}\right)$ and (b) the novel environment $\left(25^{\circ} \mathrm{C}, 45 \% \mathrm{RH}\right)$

\begin{tabular}{lrrrrr}
\hline & \multicolumn{2}{c}{ Females } & & \multicolumn{2}{c}{ Males } \\
\cline { 2 - 3 } & \multicolumn{1}{c}{ wt } & dev & & wt & dev \\
\hline $\begin{array}{l}\text { (a) Ancestral environment } \\
\text { wt }\end{array}$ & $0.0216 \pm 0.0106$ & $+0.0442 \pm 0.0379$ & & $0.0111 \pm 0.00486$ & $+0.0130 \pm 0.0183$ \\
dev & $+0.0442 \pm 0.0379$ & $0.293 \pm 0.252$ & & $+0.0130 \pm 0.0183$ & $0.136 \pm 0.132$ \\
(b) Novel environment & & & & \\
wt & $0.0404 \pm 0.0152$ & $-0.0807 \pm 0.0568$ & & $0.0149 \pm 0.00530$ & $-0.00770 \pm 0.0342$ \\
dev & $-0.0807 \pm 0.0568$ & $1.04 \pm 0.356$ & $-0.00770 \pm 0.0342$ & $1.46 \pm 0.416$ \\
\hline
\end{tabular}

Table 3 Estimates ( \pm standard errors) of 'narrow-sense' heritability $\left(h^{2}\right)$ and genetic correlation coefficients $\left(r_{\mathrm{A}}\right)$ for female and male Callosobruchus maculatus for dry emergence body weight (wt; $\mathrm{mg}$ ) and development period (dev; days) in (a) the ancestral environment $\left(30^{\circ} \mathrm{C}, 70 \% \mathrm{RH}\right)$ and (b) the novel environment $\left(25^{\circ} \mathrm{C}, 45 \% \mathrm{RH}\right)$

\begin{tabular}{|c|c|c|c|c|}
\hline & \multicolumn{2}{|c|}{ Females } & \multicolumn{2}{|c|}{ Males } \\
\hline & wt & dev & wt & $\operatorname{dev}$ \\
\hline $\begin{array}{l}\text { (a) Ancestral environment } \\
\text { wt } \\
\text { dev }\end{array}$ & $\begin{array}{l}h^{2}+0.308 \pm 0.151 \\
r_{\mathrm{A}}+0.554 \pm 0.455\end{array}$ & $\begin{array}{l}r_{\mathrm{A}}+0.554 \pm 0.455 \\
h^{2}+0.151 \pm 0.129\end{array}$ & $\begin{array}{l}h^{2}+0.377 \pm 0.164 \\
r_{\mathrm{A}}+0.334 \pm 0.409\end{array}$ & $\begin{array}{l}r_{\mathrm{A}}+0.334 \pm 0.409 \\
h^{2}+0.107 \pm 0.104\end{array}$ \\
\hline $\begin{array}{l}\text { (b) Novel environment } \\
\text { wt } \\
\text { dev }\end{array}$ & $\begin{array}{l}h^{2}+0.611 \pm 0.229 \\
r_{\mathrm{A}}-0.394 \pm 0.217\end{array}$ & $\begin{array}{l}r_{\mathrm{A}}-0.394 \pm 0.217 \\
h^{2}+0.696 \pm 0.239\end{array}$ & $\begin{array}{r}h^{2}+0.484 \pm 0.172 \\
r_{\mathrm{A}}-0.0523 \pm 0.224\end{array}$ & $\begin{array}{r}r_{\mathrm{A}}-0.0523 \pm 0.224 \\
h^{2}+0.880 \pm 0.251\end{array}$ \\
\hline
\end{tabular}

Additive genetic covariances (Table $2 a$ ) and additive genetic correlation coefficients (Table 3a) between dry emergence body weight and development period were positive for females and males, but all estimates were not significantly different from zero.

In the novel environment, estimates of additive genetic variation and heritabilities for female and male dry emergence body weight and development period (Tables $2 b$ and $3 b$ ) were significantly greater than zero. These estimates tended to be higher than those measured in the ancestral environment, significantly so for additive genetic variation of male development period $(t=3.03, P<0.01)$. Additive genetic covariances (Table $2 b$ ) and additive genetic correlation coefficients (Table $3 \mathrm{~b}$ ) between both traits were negative for females and males, but all estimates were not significantly different from zero. 
Mahalanobis $D^{2}$ comparisons of the G-matrices showed that there were significant differences between the ancestral and novel environments for each sex (female: $\chi_{3}^{2}=37.5, \quad P<0.0001$; male: $\left.\chi_{3}^{2}=50.9, P<0.0001\right)$. A similar analysis also highlighted differences between the male and female G-matrices within both the ancestral $\left(\chi_{3}^{2}=8.03\right.$, $P<0.05)$ and novel environments $\quad\left(\chi_{3}^{2}=12.3\right.$, $P<0.01)$.

\section{Discussion}

Giga \& Smith (1983) found that temperature and humidity affected development period for various Callosobruchus species on the substrate cowpea. Here, it was found that, on the substrate mung, insects not only developed sooner at a higher temperature and humidity but they also emerged heavier. For poikilotherms in general, metabolic rate is positively correlated with ingestion and assimilation rates and is higher at increased temperatures (Peters, 1983). Intuitively, organisms growing faster at higher temperatures should also grow larger, because the fecundity advantages of larger size should then outweigh the cost of having to grow for longer to achieve it (Sibly \& Atkinson, 1994). However, it is interesting to note that in a recent review of 109 studies of plants, protists, ectothermic animals and a bacterium, despite developing faster with increased temperature, over 80 per cent showed a reduction in size (Atkinson, 1994).

\section{Genetic architecture in the ancestral environment}

It was predicted that in the ancestral environment there would be significant amounts of additive genetic variation for emergence body weight and development period and significant positive genetic covariation (reflecting a genetic trade-off) between these two traits, which would explain the maintenance of this genetic variation (prediction 1, see Introduction). Estimates of additive genetic variation and $h^{2}$ were significantly greater than zero for emergence body weight, but not for development period. Estimates of additive genetic covariances and correlation coefficients were positive for both sexes, in line with the predicted genetic trade-off, but also not significantly different from zero.

There are various possible reasons why the estimates for development period were relatively low. Weight was measured to the nearest $10 \mu \mathrm{g}$, whereas development period was measured to the nearest $24 \mathrm{~h}$. Because the great majority of insects emerged over 4-5 days, development period was therefore measured on a relatively coarse scale. Also, $h^{2}$ estimates are generally lower for primary fitness characters (e.g. development period) than for morphological traits (e.g. emergence body weight) owing to relative differences in the intensity of past selection pressures (Mousseau \& Roff, 1987; Falconer, 1989; Messina, 1993). Selection is stronger on life history traits, which are more closely related to fitness and, therefore, their genetic variation is gradually reduced through evolutionary time to a relatively greater degree.

\section{Genetic architecture in the novel environment}

As gene expression is environment dependent (Strickberger, 1968), it was predicted that G-matrices would be significantly different between the ancestral and novel environments (prediction 2, see Introduction). Mahalanobis $D^{2}$ comparisons between matrices confirmed this for both sexes. It was also predicted that in the novel environment, in comparison with the ancestral environment, estimated additive genetic variation for both traits would be higher in magnitude as a result of the expression of new genes (prediction 3, see Introduction). This prediction was statistically upheld only for the development period of male insects $(t=3.03, P<0.01$, see Table 2), but also supported in female insects of the same strain (additive genetic variation doubled for emergence body weight and almost tripled for development period). Holloway et al. (1990a) found similar trends in a population of rice weevil, Sitophilus oryzae, in a novel split-pea (Pisum sativum) environment compared with an ancestral wheat (Triticum aestivum) environment.

The expression of new genes could cause genetic trade-offs to become disrupted (Bell \& Koufopanou, 1986; Holloway et al., 1990a), because in the novel environment original genotypes are likely to sort themselves out as generally poor performers and generally better performers (cf. Rose, 1982). It was therefore predicted that the positive additive genetic covariation between emergence body weight and development period in the ancestral environment would break down by becoming more negative in the novel environment (prediction 4, see Introduction). The genetic correlation coefficients were estimated at $+0.554 \pm 0.455$ and $+0.334 \pm 0.409$ for female and male insects, respectively, in the ancestral environment, but in the novel environment, these estimates became more negative and were estimated at $-0.394 \pm 0.217$ and $-0.0523 \pm 0.224$, respectively. Evidence for the existence of genetic trade-offs was therefore far stronger in the ancestral environment. 
Some of the breeding studies that have been carried out in the past failed to detect predicted genetic trade-offs because wild populations were measured after just a few generations in the laboratory, i.e. under novel environmental conditions (e.g. Murphy et al., 1983; see review by Bell \& Koufopanou, 1986).

\section{A comparison of male and female parameters within environments}

The fitness advantages of developing heavier at a cost of developing later are not so evident for males. Perhaps a heavier male may have more energy to allocate to 'mate-search' and maintenance costs, but there must be a strong selection pressure to develop earlier, as it would allow earlier mating opportunities with virgin females. It was found that male insects emerged considerably lighter but earlier than female insects. The net fitness that males obtain by emerging earlier but smaller may be greater than the net fitness that they could obtain by emerging heavier after a longer development period.

The Mahalanobis $D^{2}$ test revealed significant differences (at the $0.5-0.25$ per cent level) between the female and male G-matrices in the ancestral environment. Sex-limited G-matrix structure has been noted elsewhere (Holloway et al., 1993). It is possible that different constraints operate in the two sexes, with energy being used in different ways (Maynard Smith et al., 1985). Quantitative genetic studies have focused primarily on the female sex, but if sex differences are apparent then estimates and predictions cannot simply be extended to the population as a whole. It seems that sex is yet another dimension that must be considered during multivariate genetic analyses.

\section{Acknowledgements}

We are very grateful to Professor R.H. Smith who helped secure the funding for the project, to Professor Robert Curnow for statistical advice and to John Millard, Viv Rimmer and Mark Stares for technical assistance. Two anonymous referees provided invaluable suggestions for improving the manuscript. The research was carried out as part of a NERC studentship awarded to J. Guntrip.

\section{References}

ATKINSON, D. 1994. Temperature and organism size - a biological law for ectotherms? Adv. Ecol. Res., 25, 1-58.
BeCKer, w. A. 1984. Manual of Procedures in Quantitative Genetics, 4th edn. Academic Enterprises, Pullman, WA. BELL, G. 1984a. Measuring the cost of reproduction. I. The correlation structure of the life table of a plankton rotifer. Evolution, 38, 300-313.

BELL, G. 1984b. Measuring the cost of reproduction. II. The correlation structure of the life tables of five freshwater invertebrates. Evolution, 38, 314-326.

BELL, G. AND KOUFOPANOU, v. 1986. The cost of reproduction. Oxford Surveys in Evolutionary Biology, 3, 83-131.

BERGESON, O. AND WOOL, D. 1988. The process of adaptation of flour beetles to new environments. Genetica, 77, 3-13.

CHARLESWORTH, B. 1990. Optimization models, quantitative genetics, and mutation. Evolution, 44, 520-538.

CHARNOV, E. L. 1989. Phenotypic evolution under Fisher's fundamental theorem of natural selection. Heredity, 62, $113-116$.

DE LAGUeRIE, P., OLIVIERI, l., ATLAN, A. AND GOUYON, P.-H. 1991. Analytic and simulation models predicting positive genetic correlations between traits linked by tradeoffs. Evol. Ecol., 5, 361-369.

FALCONER, D. S. 1989. Introduction to Quantitative Genetics, 3rd edn. Longman, Harlow, Essex.

GIESEL, J. T. AND ZETTLER, E. 1980. Genetic correlation of life-historical parameters in certain fitness indices in Drosophila melanogaster: $\mathrm{rN}$, rs and diet breadth. Oecologia, 47, 299-302.

Giesel, J. T., MURPHy, P. A. AND MANLOVE, M. N. 1982. The influence of temperature on genetic interrelationships of life history traits in a population of Drosophila melanogaster: what tangled data sets we weave. $\mathrm{Am}$. Nat., 119, 464-479.

GIGA, D. P. AND SMITH, R. H. 1983. Comparative life history studies of four Callosobruchus species infesting cowpeas with specific reference to Callosobruchus rhodensianus (Pic.) (Coleoptera: Bruchidae). J. Stored Prod. Res., 19, 189-198.

HOLLOWAY, G. J. AND SMITH, R. H. 1987. Sexual selection of body weight in Sitophilus oryzae (L.) (Coleoptera: Curculionidae). J. Stored Prod. Res., 23, 197-202.

HOLLOWAY, G. J., POVEY, S. R. AND SIBLy, R. M. 1990a. The effect of new environment on an adapted genetic architecture. Heredity, 64, 323-330.

HOLLOWAY, G. J., SIBLY, R. M. AND POVEY, S. R. 1990b. Evolution in toxin-stressed environments. Funct. Ecol., 4, 289-294.

HOLLOWAY, G. J., DE JONG, P. W. AND OTTENHEIM, M. 1993. The genetics and cost of chemical defence in the two-spot ladybird (Adalia bipunctata L.). Evolution, 47, 1229-1239.

KAWECKl, T. J. 1995. Expression of genetic and environmental variation for life history characters on the usual and novel hosts in Callosobruchus maculatus. (Coleoptera: Bruchidae) Heredity, 75, 70-76.

KEMPTHORNE, O. 1957. An Introduction to Genetic Statistics. John Wiley, New York.

KNOTT, S. A., SIBLY, R. M., SMITH, R. H. AND MøLLER, H. 1995. Maximum likelihood estimation of genetic para-

(c) The Genetical Society of Great Britain, Heredity, 78, 158-165. 
meters in life-history studies using the 'Animal Model'. Funct. Ecol., 9, 122-126.

KRZANOWsKI, W. I. 1988. Principles of Multivariate Analysis. A User's Perspective. Clarendon Press, Oxford.

LANDE, R. 1979. Quantitative genetic analysis of multivariate evolution, applied to brain:body size allometry. Evolution, 33, 402-416.

LESSELLS, C. M. 1991. The evolution of life histories. In: Krebs, J. R. and Davies, N. B. (eds) Behavioural Ecology, 3rd edn, pp. 32-68. Blackwell Scientific Publications, Oxford.

LI, J. AND MARGOLIs, D. C. 1994. Responses to direct and indirect selection on aerial dispersal behaviour in Tetranychus urticae. Heredity, 72, 10-22.

LUCKINBILL, L. S., ARKING, R., CLARE, M. J., CIROCCO, W. C. AND BUCK, S. A. 1984. Selection for delayed senescence in Drosophila melanogaster. Evolution, 38, 996-1003.

MACKAY, T. F. C. 1985 . A quantitative genetic analysis of fitness and its components in Drosophila melanogaster. Genet. Res., 47, 59-70.

MAYNARD SMITH, J., BURIAN, R., KAUfFMAN, S., ALbERCH, P., CAMPBELL, J., GOODWIN, B. ET AL. 1985. Developmental constraints and evolution. Q. Rev. Biol., 60, 265-287.

MESSINA, F. J. 1993. Heritability and 'evolvability' of fitness components in Callosobruchus maculatus. Heredity, 71, $623-629$.

MøLleR, H., SMITH, R. H. AND SIBLY, R. M. 1989. Evolutionary demography of a bruchid beetle. I. Quantitative genetical analysis of the female life history. Funct. Ecol., 3, 673-681.

MOUSSEAU, T. A. AND ROFF, D. A. 1987. Natural selection and the heritability of fitness components. Heredity, 59, 181-197.

MURPHY, P. A., GIESEL, J. T. AND MANLOVE, M. N. 1983. Temperature effects on life history variation in Drosophila simulans. Evolution, 37, 1181-1192.

PETERS, R. H. 1983. The Ecological Implications of Body Size. Cambridge University Press, Cambridge.

ROFF, A. D. AND MOUSSEAU, T. A. 1987. Quantitative genetics and fitness: lessons from Drosophila. Heredity, 58, $103-118$.

Rose, M. R. 1982. Theories of life-history evolution. Am. Zool., 23, 15-23.

ROSE, M. R. 1984. Genetic covariation in Drosophila life history: untangling the data. Am. Nat., 123, 565-569. ROSE, M. R. AND CHARLESWORTH, B. 1981. Genetics of life history in Drosophila melanogaster. I. Sib analysis of adult females. Genetics, 97, 173-186.

SAS INSTITUTE INC. 1989. SAS/STAT User's Guide (Version 6, 4th edn, Volumes 1 and 2). SAS Institute, Cary, NC.

SCHEINER, S. M., CAPLAN, R. L. AND LYMAN, R. F. 1989. A search for trade-offs among life-history traits in Drosophila melanogaster. Evol. Ecol., 3, 51-63.

SEARLE, s. R. 1971. Linear Models. John Wiley, New York.

SERVICE, P. M. AND ROSE, M. R. 1985. Genetic covariation among life-history components: the effect of novel environments. Evolution, 39, 943-945.

SIBLy, R. M. AND CALOW, P. 1986. Physiological Ecology of Animals: an Evolutionary Approach. Blackwell Scientific Publications, Oxford,.

SIBLY, R. M. AND ATKINSON, D. 1994. How rearing temperature affects optimal adult size in ectotherms. Funct. Ecol., 8, 486-493.

SIMMONS, M. J., PRESTON, C. R. AND ENGELS, W. R. 1980. Pleiotropic effects on fitness of mutations affecting viability in Drosophila melanogaster. Genetics, 94, 467-475.

SMITH, R. H., LINTON, L. A. AND SIBLY, R. M. 1993. Tradeoffs and genetic correlations among life history traits: theory and simulation. In: Stokes, T. K., McGlade J. M. and Law R. (eds) The Evolution of Evolving Resources, pp. 128-144. Springer Verlag, Berlin.

SOKAL, R. R. AND ROHLF, F. J. 1981. Biometry, 2nd edn. W. H. Freeman, San Francisco.

soliman, M. H. 1982. Directional and stabilizing selection for developmental time and correlated response in reproductive fitness in Tribolium castaneum. Theor. Appl. Genet., 63, 111-116.

SOUTHGATE, B. J., HOWE, R. W. AND BRETT, G. 1957. The specific status of Callosobruchus maculatus (F.) and Callosobruchus analis (F.). Bull. ent. Res., 48, 79-89.

STEARNS, s. c. 1983. The genetic basis of differences in life-history traits among six populations of mosquitofish (Gambusia affinis) that shared common ancestors in 1905. Evolution, 37, 618-627.

STRICKBERger, M. w. 1968. Genetics. Collier Macmillan, London.

VAN NOORDWIJK, A. J. AND DE JONG, G. 1986. Acquisition and allocation of resources: their influence on variation in life history tactics. Am. Nat., 128, 137-142.

WRIGHT, s. 1931. Evolution in Mendelian populations. Genetics, 16, 97-159. 